\title{
Comprehensive Safety Guidelines for Doctors and Healthcare Workers during COVID-19
}

Kaushik Bhattacharya ${ }^{1 *}$, Neela Bhattacharya ${ }^{2}$

${ }^{1}$ CAPFs Composite Hospital BSF Kadamtala,

Siliguri, West Bengal, India

${ }^{2}$ Anandaloke Multispeciality Hospital,

Siliguri, West Bengal, India

\section{*Corresponding author's email:}

kbhattacharya10@yahoo.com

Received: 9 July 2020

Accepted: 9 December 2020

Keywords: COVID-19, PPE, healthcare workers, depression

\section{ABSTRACT}

When the coronavirus pandemic broke out, doctors approached it like another flu but ended up dying in significant numbers across the globe, resulting in the medical community getting shaken and suffering burnout and other mental issues. It is time to introspect as to how to give a healthy environment to doctors and other healthcare workers to work smoothly so that they can take care of the COVID-19 patients in a better way. A guideline is required for the safety of doctors and healthcare workers fighting the battle with COVID-19.

\section{INTRODUCTION}

The world is ill-prepared to respond to a severe influenza pandemic or any similarly global, sustained and threatening public-health emergency (Dumiak M, 2012).

When Dr Liang Wudong, Director of the Department of Otorhinolaryngology of Hubei Province, China became the first doctor to die from the COVID-19 infection on 25 January 2020, the medical community got the alarm but never realized the gravity of the situation due to this pandemic and the death and doom this virus will cause one day to the healthcare providers who are taking care of the infected patients in the hospital.

The National Health Commission of the People's Republic of China reported in February 2020 that out of the total number of COVID-19 
patients, $4.4 \%$ were healthcare workers or others who worked in medical facilities. The median age of healthcare workers (HCW) at death was 55 years and the median period from hospital admission till death was 19 days (Zhan et al., 2020). In another study from Italy, reported on 17 April 2020, the latest estimate of medical doctor deaths reached 119, which is $57.8 \%$ of total HCW deaths; followed by nurses $16.5 \%$, nurse aides $8.3 \%$ and dentists $5.8 \% ; 2$ nurses committed suicide due to unsustainable work pressure due to COVID-19 (Lapolla P et al., 2020). In India, the first case of COVID-19 was detected on 30 January 2020 and by May 2020, it had affected around 548 doctors, nurses and paramedics across the country, according to data maintained by the Government of India (Medical Dialogues Bureau, 2020). This figure excluded field workers, ward boys, sanitation workers, security guards, lab attendants, peons, laundry and kitchen staff. While the Indian Medical Association data till 29 April 2020 showed that 927 doctors were infected with COVID-19, of whom 57 died. This data does not include small private hospitals and nursing homes, general physicians, and those in the periphery of cities. By the end of May 2020, the Indian Council of Medical Research (ICMR) data portal contained the results and contact details of 23,898 symptomatic HCWs who were tested for SARS-CoV-2 infection. After excluding nonIndian nationals and missing or wrong contact details from this database, 21,402 records were obtained, with 1,073 (5\%) confirmed SARS-CoV-2-infected HCWs (Chatterjee et al., 2020). A total of 515 doctors and 90 nurses and healthcare workers had succumbed to this disease according to the report released by the Indian Medical Association in October 2020 (The Wire Staff, 2020, 2 October). More than half of those who died were less than 60 years while $30 \%$ were less than 50 years and $21 \%$ below 40 years. The risk applies not only to nurses and doctors but also to pharmacists, technicians, physiotherapists, receptionists, paramedics, attenders, ambulance drivers and other staff. According to the World Health
Organisation (WHO), the COVID-19 pandemic had hit over 22,000 healthcare workers across 52 countries and regions as early as April 2020 (IANS, 2020, 12 April). As so far there is no systematic reporting of infections among healthcare workers to the $\mathrm{WHO}$, this number is probably grossly under-represented. It has been observed globally that the average age of the physicians at death due to the coronavirus was 63.7 years and $90 \%$ were males. The countries reporting the maximum deaths of doctors were Italy (44\%), Iran (15\%), Philippines (8\%), Indonesia (6\%), China (6\%), Spain (4\%), USA (4\%) and UK (4\%) (Ing et al., 2020). The most worrying statistics of all was that the healthcare workers have a serious perception of not getting enough support from medical administrators and public health authorities while they are dealing with this pandemic and it is very important to bring out protocols and change in the system to protect the healthcare professionals (Lai et al., 2020).

So, what can be done to save the doctors and the healthcare workers from falling prey to the novel coronavirus infection?

1. Avoid stupidity - All healthcare workers need to wear Personal Protective Equipment (PPE) with perfect knowledge of donning and doffing technique, along with an N95 mask and face shield without any compromise. Any slip shot or lacunae will make the entire hospital staffvulnerable to getting exposed to the virus. The reason for the high mortality of HCWs in Italy was not only due to the sheer prevalence of the COVID-19 outbreak, but the employment of senior retired doctors to treat ill patients and finally the shortage of PPE. If there is scarcity or non-availability of PPE, those HCW should not be put on duty in the designated COVID-19 ward (Ing E.B. et al., 2020)

2. With the COVID-19 test not available freely in many parts of the world 
and the cumbersome procedure in practice in India to satisfy all the ICMR guidelines to qualify for the test, it is recommended to consider all patients to be potentially COVID-19 positive in this ongoing pandemic until and unless proven otherwise. All precautions should be in place while dealing with all the inpatients till the curve flattens (Bhattacharya \& Bhattacharya, 2020).

3. All outpatient consultations should be either through video conferencing or teleconsultation wherever possible.

4. All planned elective surgery should be avoided till the graph flattens. Only life-threatening emergency surgeries should be entertained by the hospital. Even then, a screening HR CT of the chest and/ or an RT-PCR for COVID should be obtained prior to surgery to forewarn and protect the surgeon, all OT staff and the hospital workers handling the patient.

5. Depression, anxiety, insomnia, and distress are the most common mental health issues the physicians and nurses were facing in the fever clinics in China. It is of paramount importance for the authorities to protect the mental health of the HCWs fighting the COVID-19 pandemic by setting up therapy sessions, leave off duty to recuperate, and creating a positive environment where the HCW is assured of being taken care of should he fall ill. It is especially important to promote mental wellbeing in healthcare workers exposed to COVID-19 daily especially with women, nurses, and frontline workers (Ministry of Health and Family Welfare, Government of India, 2020). COVID-19 Traumatic stress disorder is the new terminology for the Surgeons performing surgery on the COVID-19 patients in the operation theatre (Majeed et al., 2020).
6. Good infection control measures with proper sterilization can reduce the risk of transmission of infections in healthcare settings. The hospital clinic and the floor should be cleaned with sodium hypochlorite. The recommendation of $0.1 \%(1,000 \mathrm{ppm})$ in the context of COVID-19 is a conservative concentration that will inactivate most other pathogens that may be present in the healthcare setting. However, for blood and body fluids large spills (i.e. more than about $10 \mathrm{~mL}$ ) a concentration of $0.5 \%(5,000 \mathrm{ppm})$ is recommended.

7. The operation theatre should have a negative pressure airflow environment to prevent the risk of viral spread when managing a patient infected with COVID-19. High-risk aerosol-generating procedures, such as intubation, extubation or endoscopy should not be performed in a positive pressure environment (Bhattacharya, 2020)

8. As compared to the general population, doctors and healthcare workers are exposed to a high viral load due to long hours of continuous work in the hospital environment making the COVID-19 infection more serious and lethal. The system in the hospital should be such that high viral load can be minimized. WHO has called for respecting the rights to decent working conditions of HCWs to prevent them from suffering from burnout during this ongoing pandemic (Bhattacharya, 2020).

9. Aged and old physicians should avoid being frontline workers with COVID-19 patients (Gupta et al., 2020).

10. Even though scientific medical journals are considered as the best evidence to update knowledge on COVID-19, it was seen that $59.7 \%$ of Jordanian doctors believe that officials are a trustful source, 
which reflects an adequate mutual trust between hospital administrators and the doctors serving in the frontline. Therefore, it is the duty of administrators to guide all staff especially the housekeeping, ward helpers and trainees so that infection among them be minimised. A total of $40 \%$ of medical information shared on social media were fake, and so all information has to be adequately whetted before being accepted (Suleiman et al., 2020).

As the ongoing world war against coronavirus, it is especially important to maintain a fit and robust army of medical health professionals to overcome the enemy from all sides. A team of motivated and dedicated healthcare workers are of paramount importance to fight the pandemic. It is very important to frame a proper guideline for all medical professionals to decrease the incidence of healthcare workers contracting COVID-19 during work. In a COVID-19 HCW surveillance programme at University Malaya Medical Centre (UMMC) Kuala Lumpur, it was concluded that risk-based assessment, symptom surveillance and its subsequent management are the most important components in a COVID-19 surveillance programme to safeguard the health of the HCW (Wan et al., 2020).

\section{CONCLUSION}

As most COVID-19 infections were transmitted by patients in a hospital environment, innumerable medical workers who encountered the infected personnel had to be quarantined and many hospitals had to be fully or partially closed down. Death of healthcare workers is a matter of serious concern which must be addressed by the regulatory authorities and proper guideline must come out for the safety of the healthcare workers who are facing the brunt of the attack during the battle with a virus which neither has any effective medical treatment nor any vaccine for protection till today.

\section{REFERENCES}

Bhattacharya, K. (2020a). Are Surgeons in India prepared for COVID-19?. Ind J Surg, 82, 230231.

Bhattacharya, K. (2020b). Surgeon's COVID-19 traumatic stress disorder. Ind J Surg, 83, 382. https://doi.org/10.1007/s12262-020-025044

Bhattacharya, K., \& Bhattacharya, N. (2020). Health care workers facing social ostracism during COVID-19. J Ind Med Asso, 118 (8), 22 - 24.

Bielicki, J. A., Duval, X., Gobat, N., Goossens, H., Koopmans, M., Tacconelli, E., \& van der Werf, S. (2020). Monitoring approaches for health-care workers during the COVID-19 pandemic. The Lancet -Infectious Diseases, 20 (10), e261 - e267. https://doi.org/10.1016/ S1473-3099(20)30458-8

Chatterjee, P., Anand, T., Singh, K. J., Rasaily, R., Singh, R., Das, S., Singh, H., Praharaj, I., Gangakhedkar, R. R., Bhargava, B., \& Panda, S. (2020). Healthcare workers \& SARSCoV-2 infection in India: A case-control investigation in the time of COVID-19. Indian J Med Res, 151 (5), 459 - 467. https://doi. org/10.4103/ijmr.IJMR_2234_20

Dumiak, M. (2012). Push needed for pandemic planning. Bulletin of the World Health Organization, 90 (11), 800 - 801. https://doi. org/10.2471/BLT.12.021112

Gupta, S., \& Sahoo, S. (2020). Pandemic and mental health of the front-line healthcare workers: A review and implications in the Indian context amidst COVID-19. General Psychiatry, 33 (5), e100284. https://doi. org/10.1136/gpsych-2020-100284

IANS. (2020, 12 April). Over 22,000 healthcare workers infected by COVID-19: WHO. ABP Live. https://news.abplive.com/news/world/ over-22000-healthcare-workers-infectedby-covid-19-who-1195660

Ing, E. B., Xu, Q. A., Salimi, A., \& Torun, N. (2020). Physician deaths from corona virus (COVID-19) disease. Occupational Medicine (Oxford, England), 70 (5), 370 - 374. https:// doi.org/10.1093/occmed/kqaa088 
Lai, J., Ma, S., Wang, Y., Cai, Z., Hu, J., Wei, N., Wu, J., Du, H., Chen, T., Li, R., Tan, H., Kang, L., Yao, L., Huang, M., Wang, H., Wang, G., Liu, Z., \& Hu, S. (2019). Factors associated with mental health outcomes among health care workers exposed to coronavirus disease. JAMA Netw Open, 3 (3), e203976. https://doi. org/10.1001/jamanetworkopen.2020.3976

Lapolla, P., Mingoli, A., \& Lee, R. (2020) Deaths from COVID-19 in healthcare workers in Italy What can we learn? Infection Control and Hospital Epidemiology, 42 (3), 364 - 365. https://doi.org/10.1017/ice.2020.241

Majeed, A., Molokhia, M., Pankhania, B., \& Asanati, K. (2020) Protecting the health of doctors during the COVID-19 pandemic. $\mathrm{Br} J \mathrm{Gen}$ Pract, 70 (695), 268 - 269. https://doi. org/10.3399/bjgp20X709925

Medical Dialogues Bureau. (2020, 8 May). Coronavirus has infected around 548 doctors nurses and paramedics. Medical Dialogues. https://medicaldialogues.in/news/health/ coronavirus-has-infected-around-548doctors-nurses-and-paramedics- 65574

Ministry of Health and Family Welfare, Government of India. (2020). Guidelines for home isolation of very mild/ pre-symptomatic COIVD-19 cases. https://www.mohfw.gov.in/ pdf/rymildpresymptomaticCOVID19cases. pdf
Suleiman, A., Bsisu, I., Guzu, H., Santarisi, A., Alsatari, M., Abbad, A., Jaber, A., Harb, T., Abuhejleh, A., Nadi, N., Aloweidi, A., \& Almustafa, M. (2020). Preparedness of Frontline Doctors in Jordan Healthcare Facilities to COVID-19 Outbreak. International Journal of Environmental Research and Public Health, 17 (9), 3181. https://doi.org/10.3390/ijerph17093181

The Wire Staff. (2020, 2 October). IMA says at least 515 doctors have died of COVID-19. The Wire Science. https://science.thewire.in/health/ ima-515-doctors-covid-19-deaths-indiahealth-workers

Wan, K. S., Tok, P. S. K., Ratnam, K. K. Y., Aziz, N., Isahak, M., Zaki, R. A., Farid, N. D. N., Hairi, N. N., Rampal, S., Ng, C. W., Samsudin, M. F., Venugopal, V., Asyraf, M., Damanhuri, N. H., Doraimuthu, S., Arumugam, C. T., Marthammuthu, T., Nawawi, F. A., Baharudin, F., Chong, D. W. Q., ... Said, M. A. (2020). Safeguarding healthcare workers amidst COVID-19: A surveillance programme in a teaching hospital in Malaysia. [Preprint]. Bull World Health Organ. https://doi.org/10.2471/ BLT.20.275214

Zhan, M., Qin, Y., Xue, X., \& Zhu, S. (2020). Death from Covid-19 of 23 healthcare workers in China. N Engl J Med, 2020, 382. https://doi. org/10.1056/NEJMc2005696 
